\title{
ILHAS DE CALOR URBANAS NOTURNAS NO BAIRRO JARDIM MARACANÃ EM PRESIDENTE PRUDENTE (SÃO PAULO, BRASIL) ${ }^{1}$
}

\author{
NOCTURNAL URBAN HEAT ISLAND IN THE JARDIM MARACANÃ \\ NEIGHBORHOOD, PRESIDENTE PRUDENTE CITY (SÃO PAULO, BRAZIL)
}

\author{
Hiago Pereira BARBOSA ${ }^{2}$ \\ Margarete Cristiane de Costa Trindade AMORIM ${ }^{3}$
}

\begin{abstract}
Resumo: As modificações realizadas pelas atividades humanas na superfície urbana geram diferenças no balanço de energia, que por consequência, ocasionam diferenças na temperatura do ar. O principal fenômeno gerado por estas diferenças é a ilha de calor urbana (ICU), que pode ser intensificada ou amenizada de acordo com os sistemas atmosféricos atuantes e as características ambientais e urbanas presentes nas urbes e seus entornos rurais. Neste contexto, analisamos o fenômeno das ICU no bairro Jardim Maracanã em dias representativos das estações de outono e de primavera do ano de 2012 durante o período noturno. Foram registrados valores acima dos $4^{\circ} \mathrm{C}$, nas duas estações do ano sob condições de estabilidade atmosférica.
\end{abstract}

Palavras-Chavec: Clima tropical; Clima urbano; Ilha de calor urbana (ICU).

Abstract: The changes made by human activities on urban surface generate differences in energy balance, which consequently cause differences in air temperature. The main phenomenon generated by these differences is the urban heat island (UHI). According to the atmospheric systems and the environmental and urban components present in urban areas and their rural surroundings, UHI intensity can be intensified or alleviated. In this context, we analyze the phenomenon of UHI in Jardim Maracanã neighborhood on fall and spring seasons of 2012 in nighttime. In both seasons under atmospheric stability conditions, the temperature difference recorded was above $4^{\circ} \mathrm{C}$.

Keywords: Tropical climate; Urban climate; Urban heat island (UHI).

\section{Introdução}

Nos dias atuais, mais da metade da população do planeta vive em áreas urbanas, o que acarreta significativas consequências nesses espaços, que muitas vezes prejudicam a qualidade socioambiental das populações. Neste contexto, Mendonça (2004, p. 140, grifo nosso) afirma que:

O processo de urbanização atingiu, no final do século XX e início do XXI, índices bastante elevados, resultando que na atualidade a população do planeta é, majoritariamente urbana. Esta condição engendra uma série de

\footnotetext{
1 O texto apresentado é parte dos resultados do projeto de pesquisa intitulado "As características termohigrométricas no Jardim Maracanã/Presidente Prudente/SP em comparação com o ambiente rural (Processo: 12/01604-4)" financiado pela Fundação de Amparo à Pesquisa do Estado de São Paulo (FAPESP).

${ }^{2}$ Graduado (Universidade Estadual Paulista, Presidente Prudente, São Paulo, Brasil) em Geografia e Mestre (Université Rennes 2, Rennes, França) em Geografia e Planejamento Territorial. pbhiago@outlook.com ${ }^{3}$ Doutora, Professora e Livre Docente (Universidade Estadual Paulista, Presidente Prudente, São Paulo, Brasil) em Geografia. margarete.amorim@unesp.br
} 
novos e complexos problemas para a compreensão e gestão do espaço e da sociedade urbana, sendo que aqueles de ordem socioambiental se encontram destacados no contexto das cidades, particularmente daquelas de países em condições socioeconômicas de alta complexidade, como é o caso do Brasil.

Acontece de fato, uma complexificação dos problemas, já antes presentes na cidade, que agora se intensificam, sobretudo em países como o Brasil, que não há/houve uma efetivação dos meios de consumo coletivos em todas essas áreas urbanizadas.

No Brasil, o processo de urbanização juntamente com o de industrialização viram seu boom na segunda metade do século $\mathrm{XX}$, quando grande parte da população passa a se concentrar nas áreas urbanas em razão, principalmente, do êxodo rural. O deslocamento de pessoas do campo para cidade, sobretudo a partir da década de 1970, ocorre em razão da mecanização agrícola, concentração fundiária e industrialização. Com isso, o Brasil já na década de 1970 se torna um país majoritariamente urbano, no qual população urbana ultrapassa a população rural.

Atualmente, cerca de $84 \%$ da população se concentra em cidades pequenas, médias e grandes (IBGE, 2010). De acordo com o Censo Demográfico 2010,a população urbana no Brasil (ou o número de pessoas vivendo em áreas urbanas) cresceu 3\%, ou seja, em 2000 era $81 \%$ e em 2010 o valor subiu para $84 \%$.

Por meio do processo da urbanização, as cidades constituíram-se no principal cenário do desenvolvimento das relações humanas. Em tal ambiente se processam relações sociais, econômicas e culturais de um determinado contexto histórico e social, onde os processos de produção provocam constantes modificações no espaço urbano, e consequentemente no clima da cidade (SAYDELLES, 2005).

O crescimento da população e da estrutura urbana não levou em consideração, em grande parte das cidades brasileiras, as características físicas do ambiente em que essas estão inseridas, para elaboração de um planejamento urbano e ambiental adequado. Desta forma, se vê a precarização da qualidade de vida urbana, onde são os citadinos os que mais sofrem com situações de desconforto térmico e diversos prejuízos, de cunho material ou humano, à sua integridade de vida.

Situações de risco ao desconforto térmico e à formação de ilhas de calor intensas podem ser observadas como condições naturais em todas as cidades brasileiras, mas a vulnerabilidade social a estes eventos é bastante seletiva; ou seja, as repercussões sobre o desconforto térmico se fazem notar principalmente sobre a população de menor poder 
aquisitivo, uma vez que esta não possui as condições econômicas, técnicas e científicas frente a influência do clima sobre suas vidas (MENDONÇA, 2010).

As cidades brasileiras por apresentarem em sua maioria clima do tipo tropical com alternâncias de períodos secos e úmidos são afetadas, principalmente, por efeitos de chuvas intensas, ondas de calor e, nos grandes centros urbanos, episódios de poluição do ar. Estes efeitos afetam de maneira direta a saúde (física, mental e bem-estar) dos citadinos, seja via doenças hídricas, respiratórias, circulatórias e até mesmo problemas na estrutura urbana e perda de vida humanas.

As temperaturas elevadas contribuem para o desconforto térmico da população especialmente nos episódios de sistemas atmosféricos que naturalmente geram desconforto. Nos ambientes tropicais, não só os eventos extremos de temperatura e umidade do ar podem provocar desconforto, mas também os episódios habituais (AMORIM, 2011, p. 164).

Uma das temáticas mais estudadas na climatologia urbana, internacionalmente e nacionalmente, são as interações entre a superfície urbana e a atmosfera, o que propicia o surgimento do fenômeno de ilha de calor urbana.

De acordo com Lucena (2013), o calor característico das áreas urbanas, quando comparadas com seus arredores (não-urbanizados), geralmente, refere-se ao aumento na temperatura do ar, podendo igualmente fazer referência ao calor da superfície é denominado ilha de calor urbana.

A ilha de calor caracteriza-se por três aspectos principais: forma, intensidade e localização do seu núcleo mais quente. Esses aspectos são distintos em cada cidade, em função do momento do dia e da época do ano, do tempo atmosférico, da localização geográfica, incluindo sua morfologia natural, como morros, corpos hídricos e áreas verdes, e das propriedades térmicas dos materiais que compõem a superfície urbana (LUCENA, 2013, p. 32).

As transformações efetuadas na superfície urbana alteram o balanço de energia na escala local ocasionando diferenças espaciais e temporais nos valores térmicos observados na cidade (MONTEIRO, 1976; OKE, 1987), seja a partir de comparações entre o rural e o urbano, como também na escala do intraurbano.

Diversos autores concordam que a cidade modifica o balanço de energia na escala local, alterando drasticamente as características climáticas locais (MONTEIRO,1976; OKE, 1978), sendo a ilha de calor urbana, o fenômeno mais significativo destas alterações. 
Figura 1 - Perfil clássico de uma ilha de calor urbana.

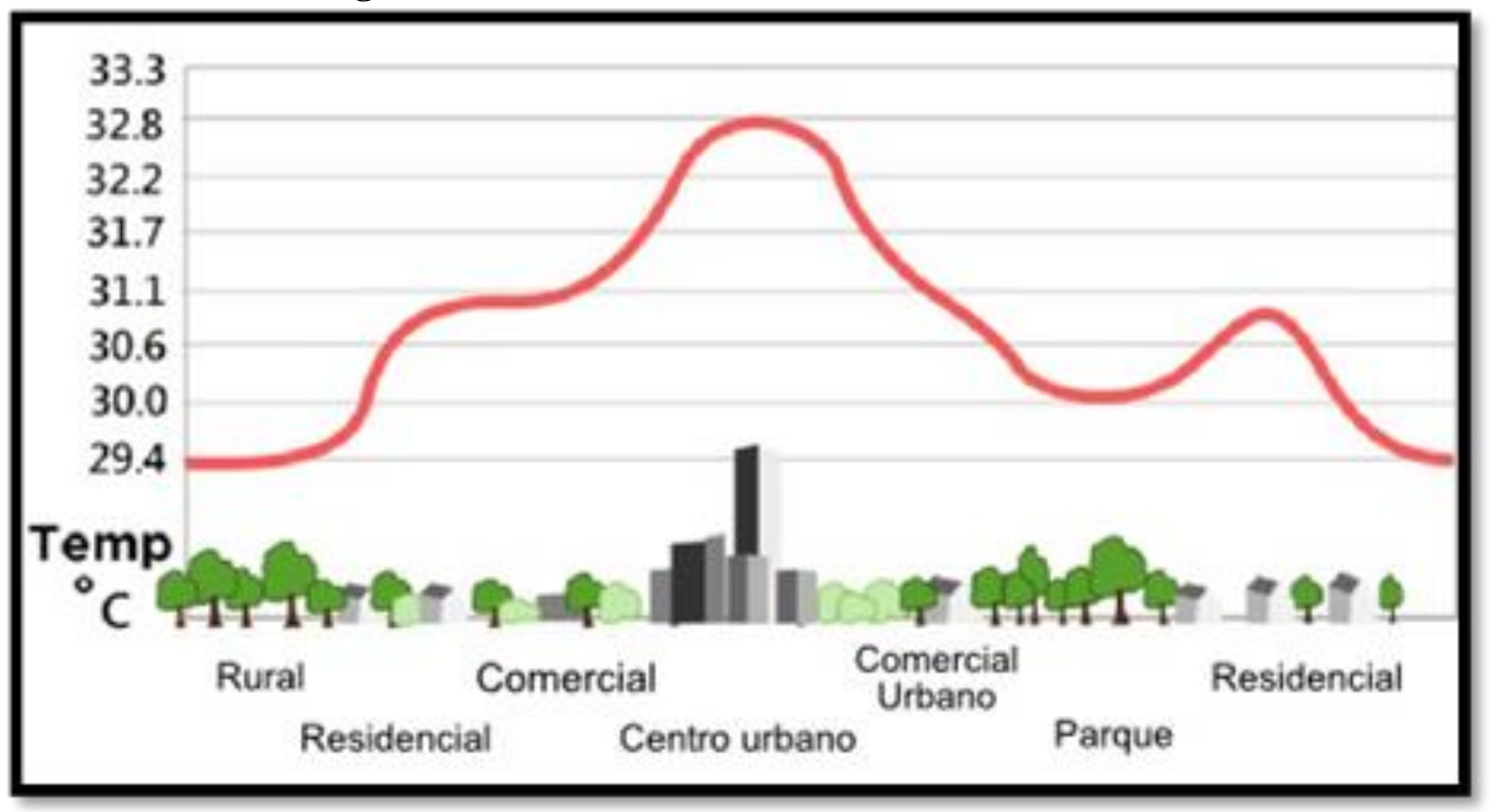

Fonte: Adaptado de EPA (United States Environmental Protection Agency).

O objetivo deste artigo é analisar episódios de ilhas de calor urbanas em dias representativos das estações do outono e da primavera durante o período noturno no bairro Jardim Maracanã e em uma zona rural situada fora da malha urbana, no município de Presidente Prudente, no oeste do Estado de São Paulo.

\section{Breve histórico dos estudos em climatologia urbana}

As primeiras preocupações com a temática de clima urbano surgiram antes da Revolução Industrial. O mais antigo vestígio sobre o clima urbano pode ser encontrado em Londres do século XVII com Evelyn em 1661, em sua obra Fumifugium que tratou do tema da poluição atmosférica.

Gartland (2008) apresenta os primeiros documentos sobre estudos de clima urbano, sobretudo os relacionados ao aquecimento das áreas urbanizadas em comparação com áreas rurais.

A primeira documentação de calor urbano aconteceu em 1818, quando o estudo revolucionário sobre o clima de Londres realizado por Luke Howard detectou um "excesso de calor artificial" na cidade, em comparação com o campo. Emilien Renou fez descobertas similares sobre a cidade de Paris durante a segunda metade do século XIX, e Wilhelm Schmidt encontrou 
essas condições em Viena no início do século XX. Nos Estados Unidos, estudos sobre ilhas de calor começaram na primeira metade do século XX. (p. 9).

García (1996) aponta que o início da climatologia urbana moderna começou em meados do século XIX e que os estudos se consolidaram com obras de caráter mais geral a partir do século XX, como o estudo de Kratz em 1937: Das Stadtkilma, e o de Tony Chandler, The Climate of London, publicado no ano de 1965.

No Brasil, os estudos de clima urbano se iniciaram com Carlos Augusto de Figueiredo Monteiro, em 1970, na pós-graduação da Universidade de São Paulo (USP), com a disciplina "Problemas de Climatologia Urbana Aplicada ao Brasil". A proposta teórica metodológica elaborada por Carlos Augusto de Figueiredo Monteiro, em 1976, sugere uma análise integrada e sistêmica do espaço geográfico, tendo como interação a relação homem-natureza na formação de uma atmosfera urbana.

Já nos anos 1970-80, dois autores são fundamentais para os estudos de climatologia urbana: Timoth Oke e Helmut E. Landsberg, com suas obras Boundary Layer Climates e The Urban Climate, nos anos de 1978 e 1987, respectivamente. Os autores contribuíram para a base teórica da origem e da compreensão dos mecanismos de formação da ilha de calor urbana, além de também colocarem em evidência o aspecto multiescalar para a compreensão deste fenômeno.

\section{Caracterização da área de estudo}

Segundo o Censo Demográfico do Instituto Brasileiro de Geografia e Estatística (IBGE, 2010), Presidente Prudente possui 207.625 mil habitantes, sendo que cerca de 203 mil habitantes vivem na zona urbana. O município apresenta grau de urbanização de 97,96\% e densidade demográfica de 372,52 habitantes por $\mathrm{Km}^{2}$.

Apresenta uma superfície de $563 \mathrm{~km}^{2}$, sendo que $16,56 \mathrm{~km}^{2}$ estão em perímetro urbano. Localizada no oeste do estado de São Paulo (figura 2), a $22^{\circ} 07^{\prime} 04$ ”' de latitude sul e $51^{\circ} 22^{\prime} 57^{\prime}$ ' de longitude oeste, com distância de aproximadamente $558 \mathrm{~km}$ da capital São Paulo (IBGE, 2014). 
Figura 2 - Localização do Município de Presidente Prudente no Estado de São Paulo e no Brasil.
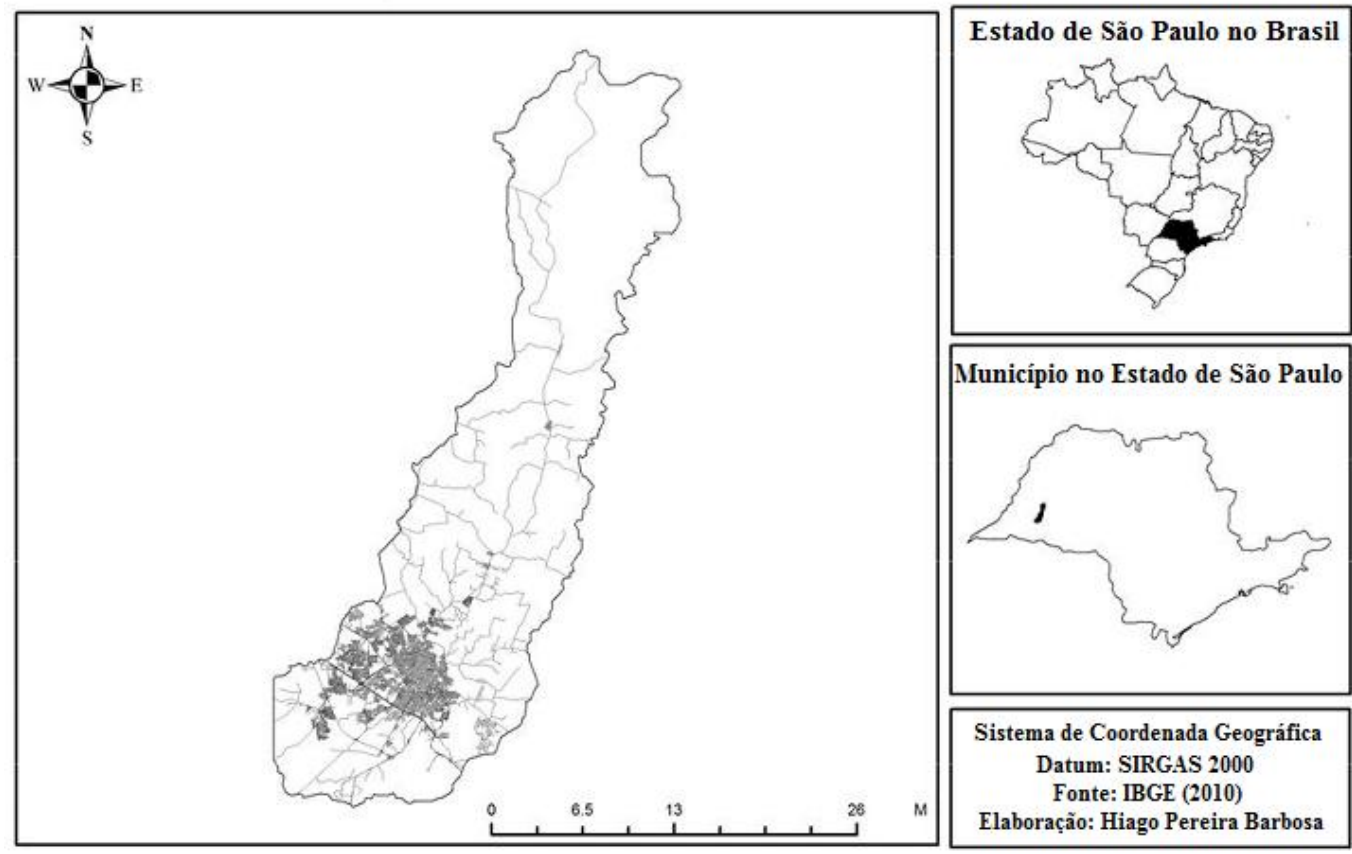

Fonte: Organização própria dos autores.

No que concerne aos aspectos climáticos Sant'Anna Neto e Silva (2011) realizaram uma classificação climática para a raia divisória dos estados de São Paulo, Paraná e Mato Grosso do Sul, caracterizando a área onde se situa a cidade de Presidente Prudente, como a unidade climática III (ou Domínio Climático do extremo oeste Paulista).

A mesma é marcada por intensas chuvas que ocorrem de dezembro a fevereiro. O período mais seco é formado pelo trimestre de junho a agosto e as maiores temperaturas não ocorrem nos meses de verão, e sim, durante os meses de setembro e outubro. Esta unidade climática se apresentou sob o domínio da tropical atlântica a maior parte do ano. [...] a área é influenciada o ano todo pela massa tropical continental, com índices mais expressivos durante todo o mês de novembro e com maior frequência de participação de instabilidades tropicais de janeiro a março. (Sant'anna Neto e Silva, 2011: 125).

Quanto a caracterização das ilhas de calor urbanas no município de Presidente Prudente, diversos estudos ja foram realizados (AMORIM, 2000; AMORIM, 2005; AMORIM, 2015; CARDOSO E AMORIM, 2018; AMORIM, DUBREUIL e CARDOSO, 2015, AMORIM, 2019) a partir de diferentes técnicas de estudo, tais como análises estatísticas, sistemas de informação geográfica, sensoriamento remoto, transectos móveis, dentre outros. Presidente Prudente apresenta uma heterogeneidade de paisagens, áreas 
EM

QUESTÃO

construídas com diferentes materiais de inércia térmica, taxa de arborização relativamente baixa, dentre outras, que podem gerar diferencas na temperatura do ar acima dos $10^{\circ} \mathrm{C}$ (AMORIM, DUBREUIL e CARDOSO, 2015).

A área de estudo escolhida para o registro dos dados meteorológicos referentes ao ambiente urbano localiza-se na porção noroeste da cidade de Presidente Prudente (Figura 3). Esse bairro foi escolhido por apresentar diferenças no uso e ocupacão do solo, na altitude, nas taxas de arborização e na densidade démografica na escala de um bairro. O bairro Jardim Maracanã foi implantado no final da década de 1980 e teve crescimento populacional mais acentuado a partir dos anos 2000, com implantação de estabelecimentos comerciais e serviços, sobretudo ao leste do bairro.

Figura 3 - Localização dos Pontos de Registro dos Dados Meteorológicos no Bairro Jardim

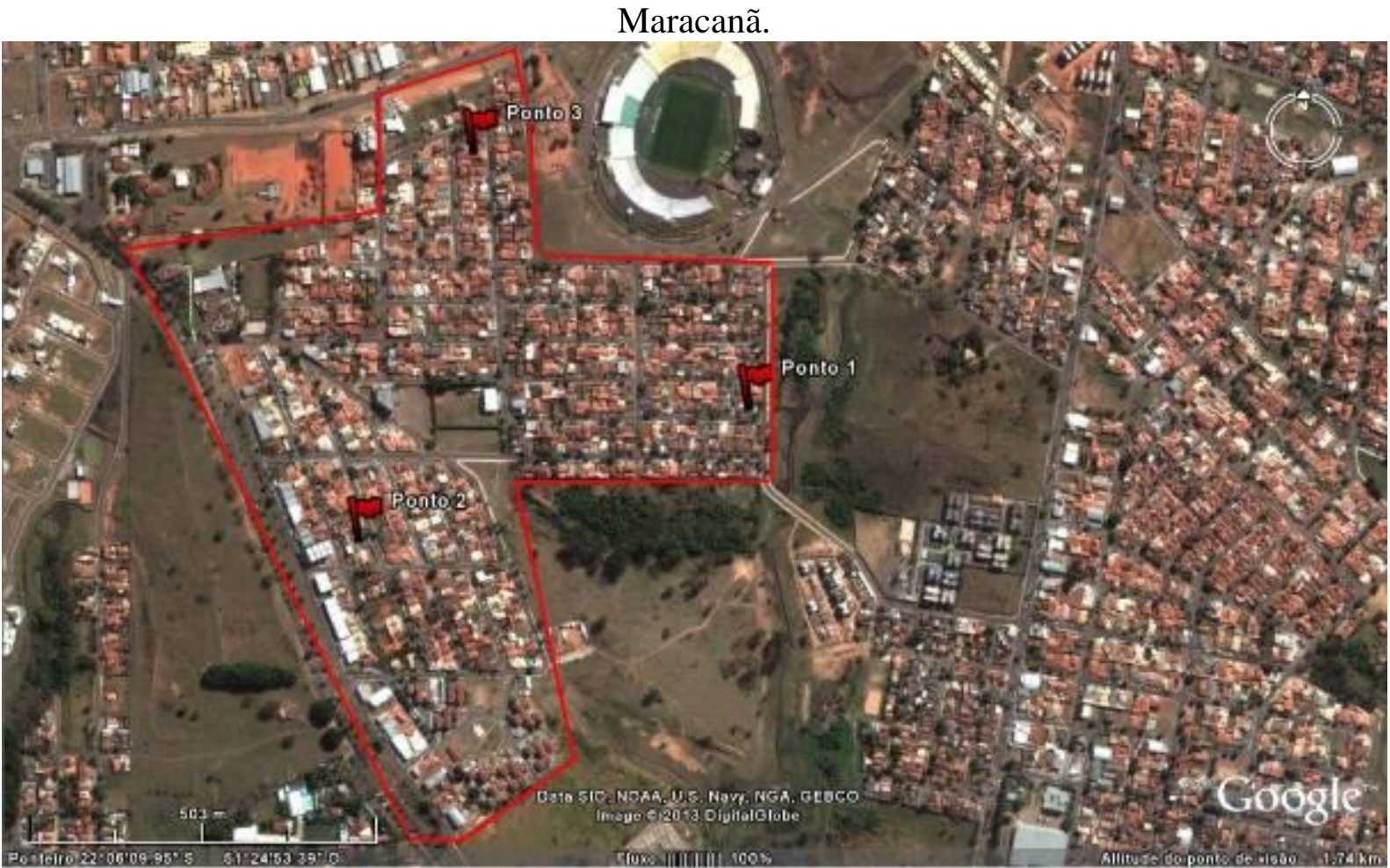

Fonte: Google Earth TM mapping service/NASA/TerraMetrics copyright. Acesso em janeiro de 2012.

A área leste do bairro está próxima de um fundo de vale com canalização aberta. Já a área norte do bairro está situada em um divisor de águas, sendo a área com maior altitude. Diferenças no uso e ocupação do solo aliados aos fatores geoecológicos presentes na zona de estudo foram essenciais para a escolha dos pontos de registro dos dados meteorológicos. Todos os pontos de registro estavam localizados em áreas privadas e as condições de tráfego de veículos durante as horas de coleta eram mínimas. 
O ponto 1 está localizado nas proximidades de um fundo de vale. O curso d'agua é um afluente que deságua em um importante córrego da cidade, o Colônia Mineira. Seu entorno é constituído por lotes residenciais com vegetação arbórea no interior e na calçada. Possui também vegetação em quantidade significativa ao leste e ao sul. $\mathrm{O}$ uso do solo predominante é residencial, com ocupação destinada as áreas verdes e espaços não construídos em diversos lotes (Figura 4). O ponto está situado a 420 metros acima do nível do mar.

O ponto 2 está localizado à oeste do bairro. Seu entorno é constituído pelo padrão de uso do solo do tipo residencial, com presença de lotes comerciais e de serviços, principalmente no eixo da Avenida Salim Farah Maluf (localizada a esquerda da Figura 4). A vegetação desta área é incipiente, sendo poucos os lotes que possuem parte do quintal ou da calçada com superfície arbórea. A localização do ponto está numa área a 447 metros acima do nível do mar.

O ponto 3 está localizado ao norte do bairro, o seu entorno é constituído pela predominância de uso do solo do tipo residencial, com incipiente uso comercial. A vegetação da área é pouco presente na maioria dos lotes, alguns apenas apresentam árvores nas calçadas e no interior dos quintais, não sendo significativos se comparados aos outros dois pontos (Figura 3). Há presença de lotes vazios, sobretudo com áreas em construção de residências e solos expostos. O ponto está localizado a 467 metros acima do nível do mar.

O ponto rural localiza-se na área sudeste de Presidente Prudente, fora da malha urbana, apresentando como características de entorno, uma cobertura vegetal do tipo rasteira e arbórea (Figura 4).

A fim de melhor caracterizar a área de estudo, foram preparadas cartas de uso e ocupação do solo para o bairro Jardim Maracanã. A primeira diz respeito ao uso do solo e é composta das seguintes categorias: espaço aberto de edifícios, terrenos não urbanizados, uso comercial, uso misto, uso residencial e uso de serviços. A segunda refere-se ao uso do solo representado por valores percentuais que variam entre 0 e $100 \%$, assim divididos em cinco classes: 0 - 20\%, $21-40 \%, 41-60 \%, 61-80 \%$ e $81-100 \%$.

Os dados utilizados para elaborar as cartas foram coletados através da observação de campo na área de estudo e com a ajuda das imagens de satélite do Google Earth. Como as imagens de satélite são datadas de agosto de 2011, a observação de campo foi necessária para atualizar as informações contidas nas cartas, tanto sobre o uso do solo quanto sobre a ocupação do solo. 
Figura 4 - Localização dos Pontos de Registro dos Dados Meteorológicos.

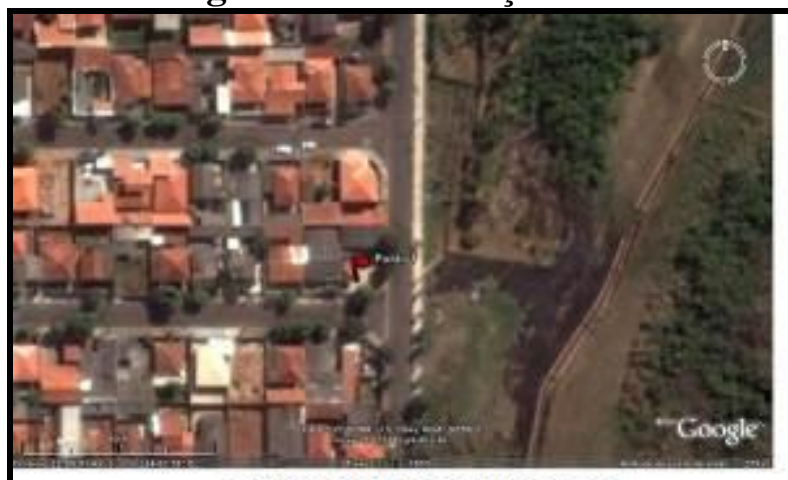

PONTO DE REGISTRO 1

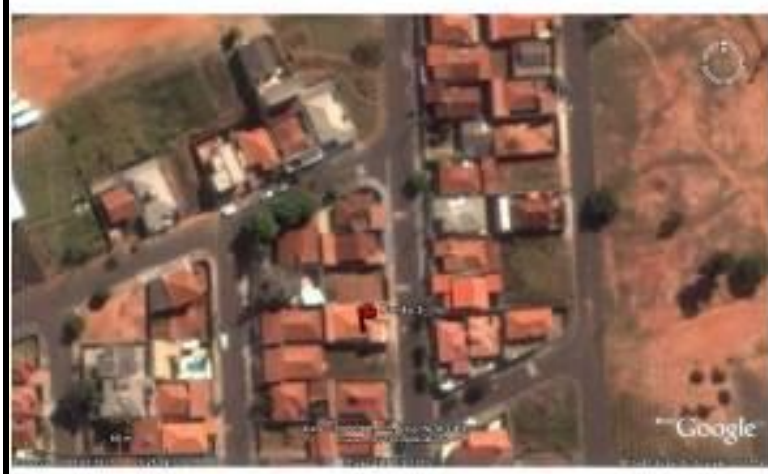

PONTO DE REGISTRO 3

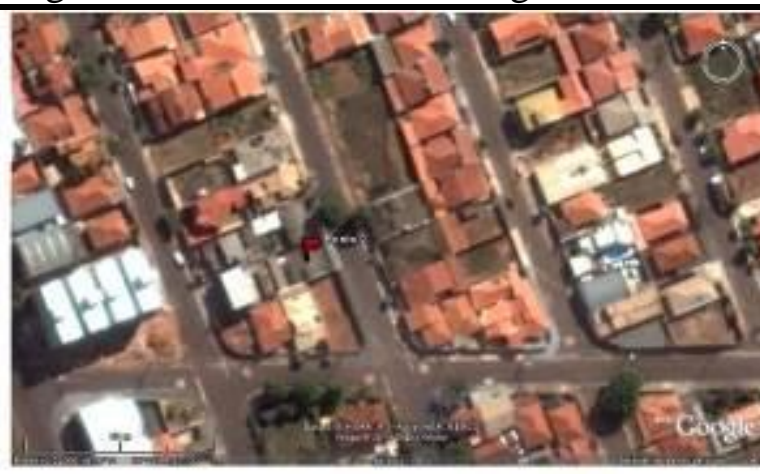

PONTO DE REGISTRO 2

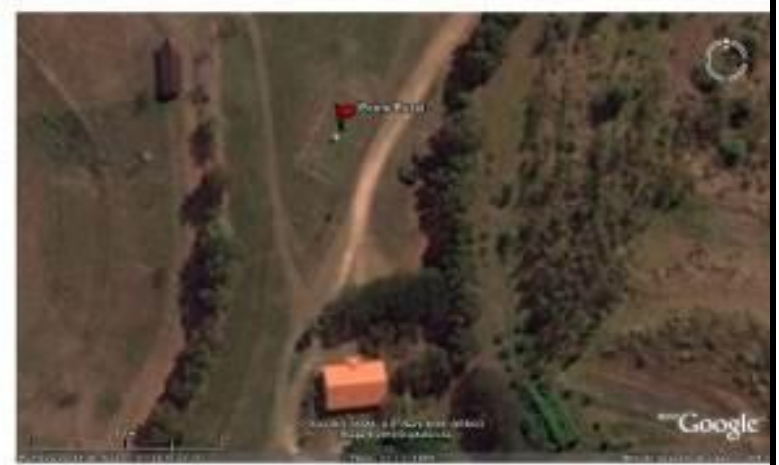

PONTO DE REGISTRO RURAL

Fonte: Google Earth TM mapping service/NASA/TerraMetrics copyright. Acesso em janeiro de 2012.

A carta de uso do solo foi desenvolvida a partir da planta no bairro Jardim Maracanã e foi classificada lote por lote de acordo com a seguinte classificação para a área de estudo, adaptada de Ugeda Júnior (2011).

- $\quad$ Espaços livres de edificações: praças, parques, sistemas de lazer, áreas institucionais, ou seja, sem presença alguma de edificações ou áreas construídas;

- $\quad$ Lotes não construídos: são os lotes passíveis de construção, mas que se encontram não utilizados, contém apenas um cercamento ou presença de muros;

- Uso comercial: lojas, bares, padarias, restaurantes, farmácias, postos de combustível, papelarias, academias, lanchonetes dentre outros;

- $\quad$ Uso misto: são os lotes com uso residencial, porém os moradores destinam parte para a realização de comércio e/ou serviços;

- $\quad$ Uso residencial: residências unifamiliares ou coletivas;

- Uso de serviços: madeireiras, oficinas mecânicas, serralherias, salões de beleza, igrejas dentre outros. 
EM

QUESTÃO

A análise da carta de uso do solo (Figura 5) revela uma predominância de uso comercial e de serviços na parte oeste e de lotes não construidos na parte norte da área de estudo. Deve-se notar que as áreas destacadas em amarelo (uso misto) na parte central e noroeste da carta são áreas institucionais públicas com sistemas recreativos, mas há ocupação da área construída, portanto foi classificada como uso misto. A maior área ao sul do bairro é destinada ao uso residencial, mas estas não são térreas, são edifícios de 6 pavimentos construídos pelo programa CDHU (Companhia de Desenvolvimento Habitacional e Urbano). Observa-se que no ano de 2012, havia a predominância de uso residencial na área de estudo.

Figura 5 - Carta de uso do solo do bairro Jardim Maracanã com indicação dos três pontos de registro de temperatura do ar.

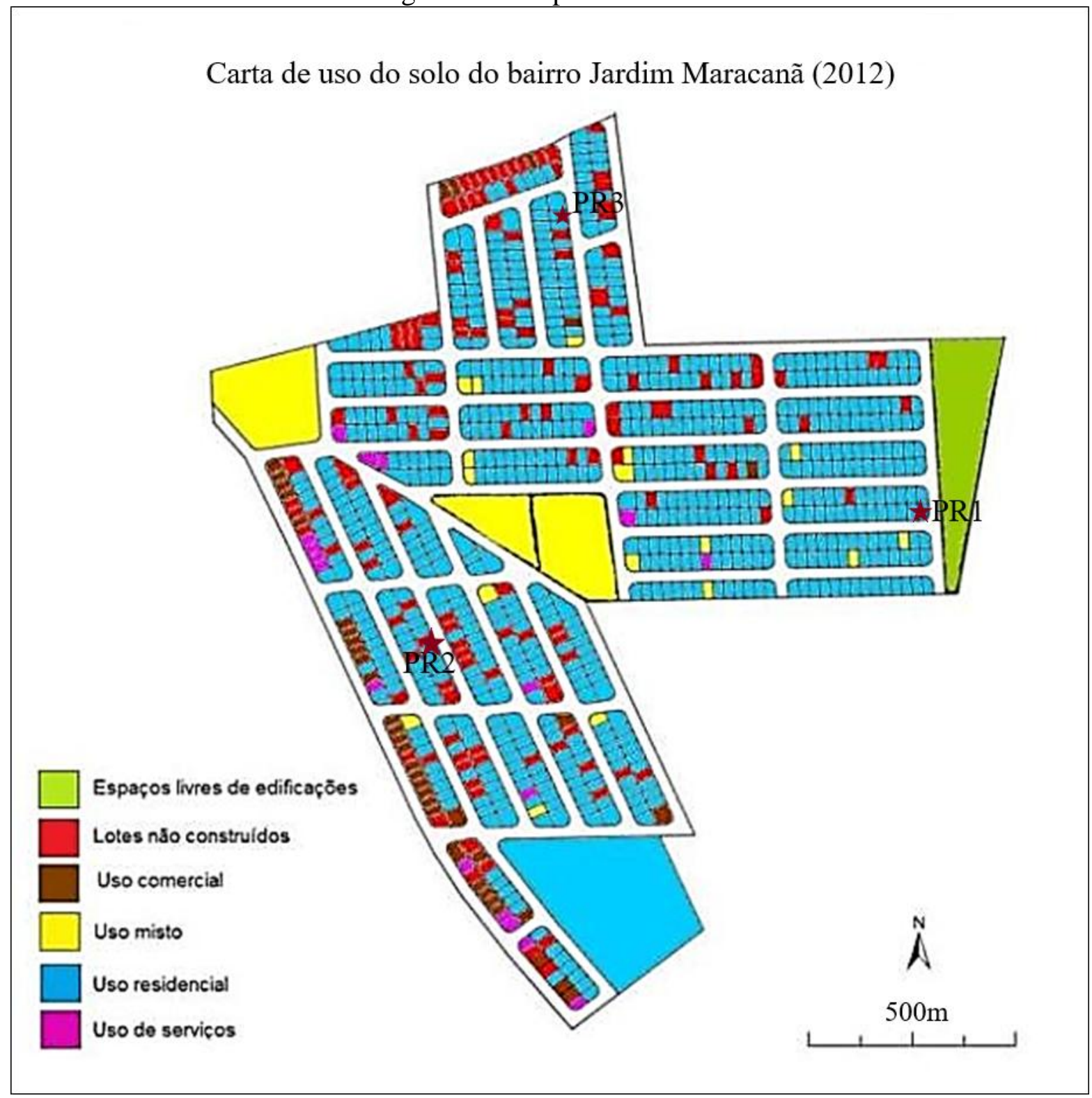

Fonte: Google Earth TM mapping service/NASA/TerraMetrics copyright (2011) e observação de campo (2012). 
EM

QUESTÃO

V.14 N. $01 \bullet 2021$

pág. 137-159

O uso do solo (Figura 6) refere-se geralmente a índices e padrões de construção, o que envolve examinar as porcentagens de construção existentes em cada lote. Esta análise foi realizada por observação de campo e de acordo com uma tabela de critérios que será explicada a seguir.

Figura 6 - Carta de ocupação do solo do bairro Jardim Maracanã com indicação dos três pontos de registro de temperatura do ar.

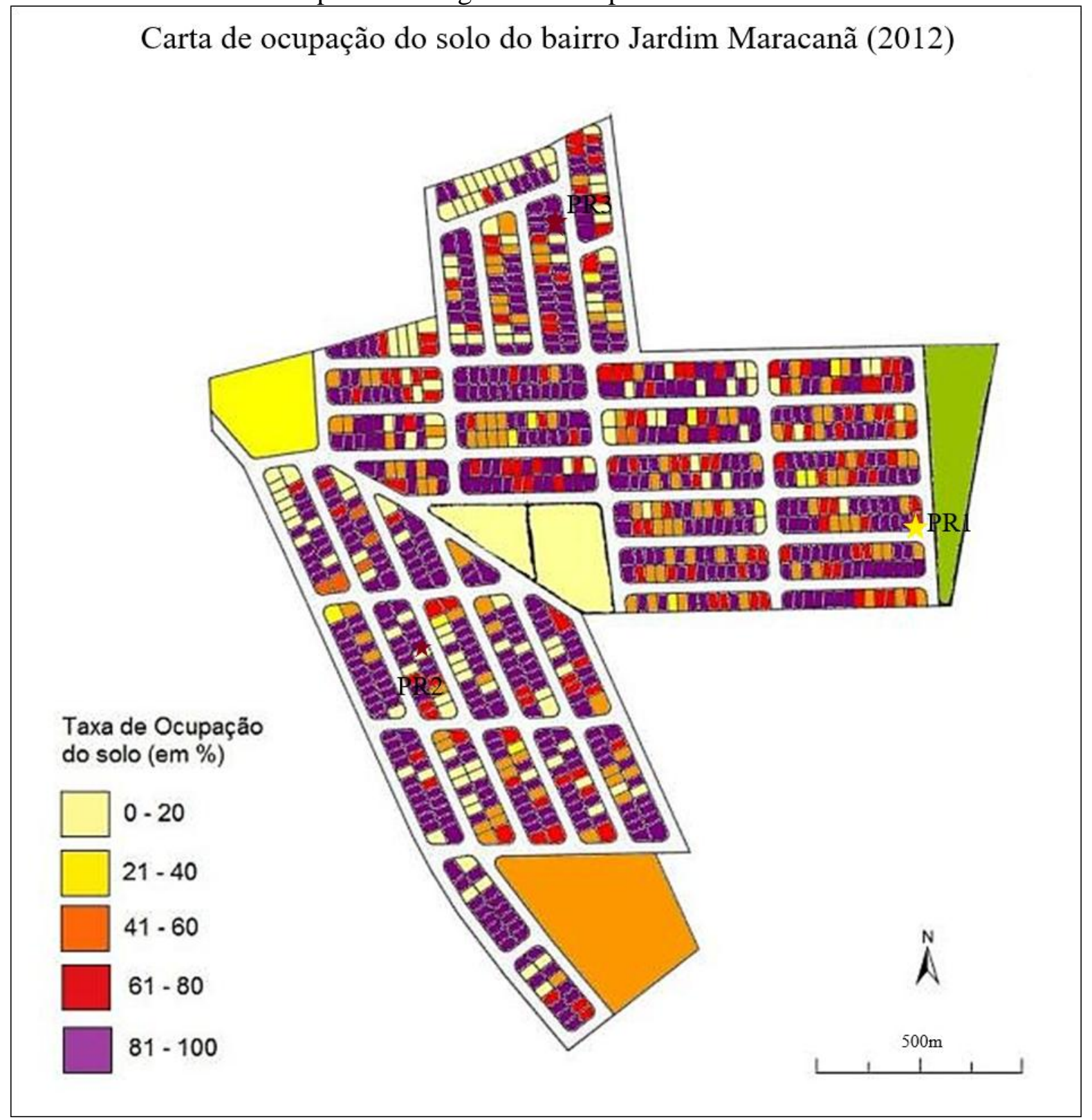

Fonte: Google Earth TM mapping service/NASA/TerraMetrics copyright (2011) e observação de campo (2012).

O primeiro fator a ser analisado foi a densidade de construção do lote, caso o lote fosse totalmente construído com ausência de vegetação no interior do lote e não das calçadas, foi considerado dentro da taxa de ocupação de 81 a 100\%. Lotes com áreas construídas e 
pequenas áreas destinadas a arborização no interior do lote e/ou presença de piscinas se encaixou na taxa de ocupação de 61 a $80 \%$. Os lotes com presença maior de áreas destinadas a arborização no interior do lote e presença de solos expostos ou com gramados foi classificado dentro da taxa de ocupação de 41 a 60\%. Os valores de taxa de ocupação de 21 a $40 \%$ foram considerados por apresentarem lotes com grande presença de arborização no seu interior ou áreas expostas, sem construção. Os lotes com inexistência de construção, ou como são popularmente chamados de terrenos baldios foram classificados com valor de taxa de ocupação entre 0 e $20 \%$.

Deve-se notar que na análise realizada, não foram consideradas árvores nas calçadas, mas sim aquelas presentes dentro dos lotes. Outro aspecto que deve ser destacado é que esta carta é apenas uma estimação das taxas de ocupação do solo na área de estudo.

Há a predominância de taxas de ocupação do solo entre $61 \%$ a $80 \%$ e $81 \%$ a $100 \%$, o que pode refletir amplamente no ambiente interno das residências e influenciar na qualidade de vida dos residentes. Embora não seja um conjunto habitacional popular, o bairro Jardim Maracanã tem altas taxas de ocupação do solo, o que significa que na maioria dos lotes há uma predominância de áreas construídas, impermeabilizadas em detrimento de áreas com vegetação.

\section{Procedimentos metodológicos}

Os materiais utilizados para o registro dos dados na área urbana, foram os registradores automáticos de temperatura e umidade relativa do ar do tipo Humiditytemperature logger, da marca ThermaData ${ }^{\mathrm{TM}}$ e do modelo HTD D10450507 (figura 7). Os dados referentes a área rural foram coletados por uma estação meteorológica automática do tipo Vantage PRO 2 da marca Davis Instruments.

Figura 7. Registrador automático de temperatura e umidade relativa do ar.

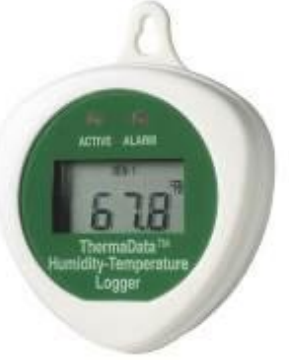

Fonte: https://www.thermometersdirect.co.uk/humidity-temperature-data-logger-thermadata-htd.html. Acesso em maio de 2019. 
Os equipamentos utilizados para o registro dos dados foram acoplados internamente em um abrigo meteorológico denominado de "Abrigo de baixo custo (Abc)" de ventilação passiva (figura 8) desenvolvido por Armani e Galvani (2006). O abrigo ABC foi construído com chapa de ferro galvanizado de $0,5 \mathrm{~mm}$ de espessura, cujo modelo é inspirado ao 41003 10-Plate Gill Radiation Shield da Campbell (Armani e Galvani, 2006) e a estrutura do abrigo era de $11,5 \mathrm{~cm}$ de altura e $18 \mathrm{~cm}$ de diâmetro e, posteriormente a construção, foi pintada na cor branca (Hoppe et al., 2015).

Figura 8 - Abrigo meteorológico de baixo custo ABC.

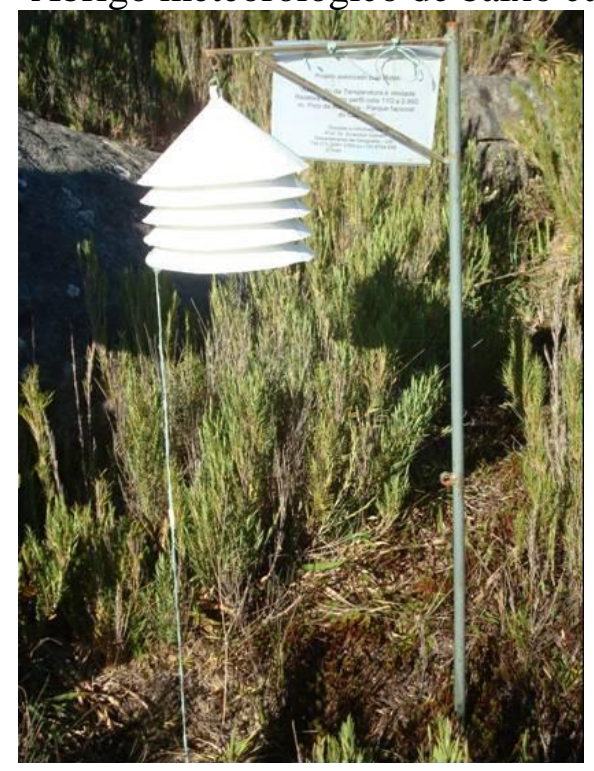

Fonte: Lima, Galvani e Falcão (2010).

O tratamento dos dados obtidos em campo realizou-se por meio de uma análise comparativa dos dados registrados nas áreas urbana e rural. Para a identificação das diferenças térmicas, realizou-se o cálculo da diferença do valor de cada ponto urbano em relação ao rural $\left(\mathrm{VALOR}_{\mathbf{U}}-\mathrm{VALOR}_{\mathbf{R}}\right)$.

A partir desta etapa, foi possível a elaboração de gráficos de barras que representam as diferenças de temperatura. Os valores negativos correspondem aos maiores valores registrados no rural, enquanto que os valores positivos correspondem aos maiores valores registrados no urbano.

Os sistemas atmosféricos atuantes na região durante o período analisado foram identificados por meio das imagens de satélite GOES $12^{4}$ e das análises sinóticas disponibilizadas no site do INPE (Instituto Nacional de Pesquisas Espaciais) diariamente. As

\footnotetext{
${ }^{4}$ Disponíveis em: http://satelite.cptec.inpe.br/acervo/goes.formulario.logic 
cartas sinóticas de superfície da Marinha do Brasil ${ }^{5}$ também foram utilizadas para o auxílio na identificação da circulação atmosférica regional.

A escolha dos horários de registro da temperatura do ar reflete a intensidade máxima da ilha de calor urbana, conforme declarado na literatura nacional e internacional, então às 21h. Em complemento, os horários de $1 \mathrm{~h}$ e das $5 \mathrm{~h}$ foram escolhidos para representar outros intervalos do período noturno que também mostram diferenças significativas entre as temperaturas do ar urbana e rural. Além disso, o uso de abrigos meteorológicos de baixo custo $\mathrm{ABC}$ não fornece dados fiáveis durante o período diurno em áreas urbanas devido à sua composição metálica e seu uso prioritário em áreas florestais.

\section{Diferenças térmicas em estações de transição no período noturno}

No horário da $1 \mathrm{~h}$ as diferenças térmicas foram mais significativas na estação da primavera, pois houve uma maior variação da temperatura do ar entre o campo e a cidade. As diferenças térmicas na estação do outono variaram de $-2^{\circ} \mathrm{C}$ a $3^{\circ} \mathrm{C}$, enquanto que na estação da primavera a variação esteve entre os valores de $-1^{\circ} \mathrm{C}$ a $4^{\circ} \mathrm{C}$.

Destaca-se na estação do outono as diferenças negativas do ponto 1 em comparação com o rural, ocasionadas pelas suas características geoecológicas, por estar situado em uma área de fundo de vale e apresentar uma presença de vegetação significativa, possibilitando então o registro de temperaturas menores que as registradas no campo.

As diferenças negativas na primavera à $1 \mathrm{~h}$ foram registradas apenas em dois dias, ocasionadas pela influência de sistemas atmosféricos instáveis - Cavado e Frente Polar Atlântica (FPA). Ressalta-se que o ponto 1 apresentou as menores diferenças em comparação com o campo, como também episódios em que não houve o registro de diferença térmica.

Destacamos que em dias representativos do outono as diferenças foram menores se comparadas aos dias representativos da primavera. Possivelmente, com maior nebulosidade presente no mês de outubro, o calor estocado durante o dia ficou armazenado na atmosfera durante a noite.

De fato, o que ocorre também é que no campo a liberação do calor ocorre de maneira mais eficiente e rápida, enquanto que na cidade os materiais constituintes desse ambiente tendem a se resfriar de maneira mais lenta, ocasionando assim diferenças térmicas.

\footnotetext{
${ }^{5}$ Disponíveis em: https://www.marinha.mil.br/chm/dados-do-smm-cartas-sinoticas/cartas-sinoticas 
Nos gráficos 1 e 2 estão apresentadas as informações sobre as diferenças térmicas entre os pontos urbanos e o rural em dias representativos da estação do outono e da primavera à $1 \mathrm{~h}$.

Gráfico 1 - Diferenças Térmicas Urbano-rural em Dias Representativos do Outono à 1h.

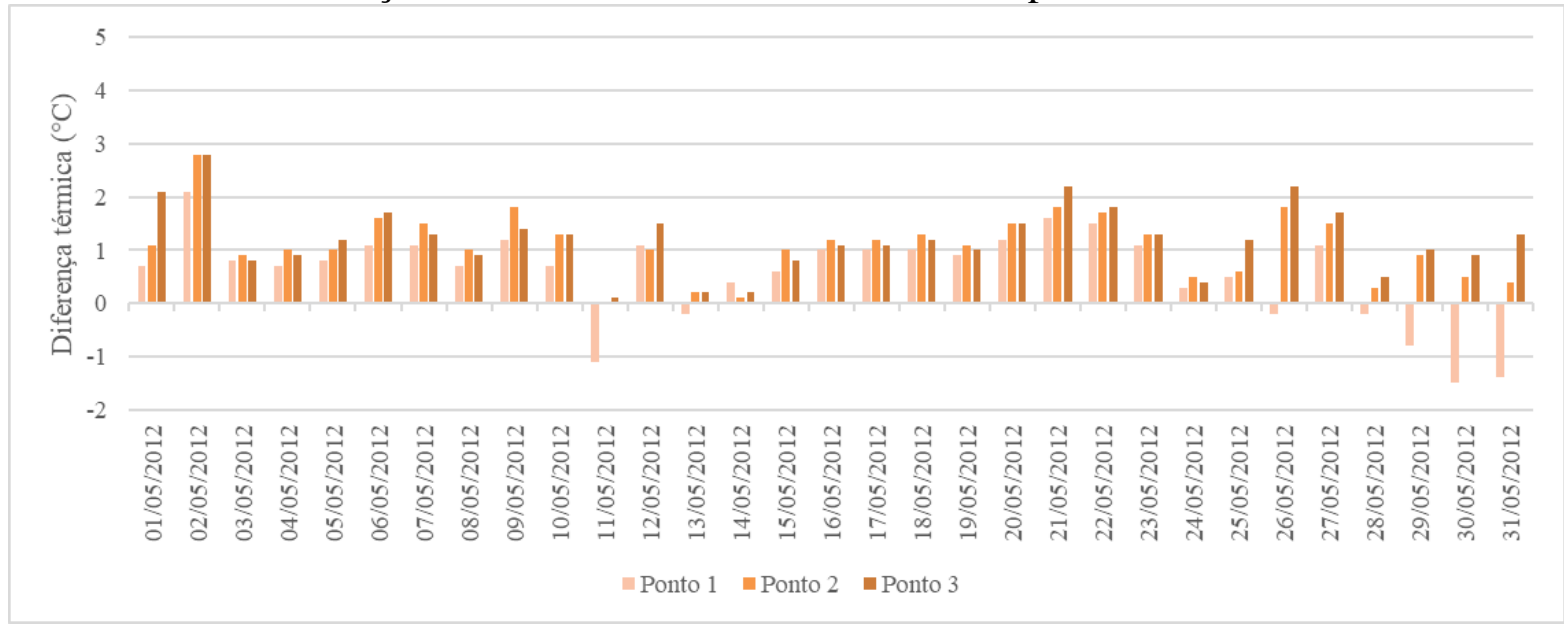

Fonte: autores.

Gráfico 2 - Diferenças Térmicas Urbano-rural em Dias Representativos da Primavera à 1h.

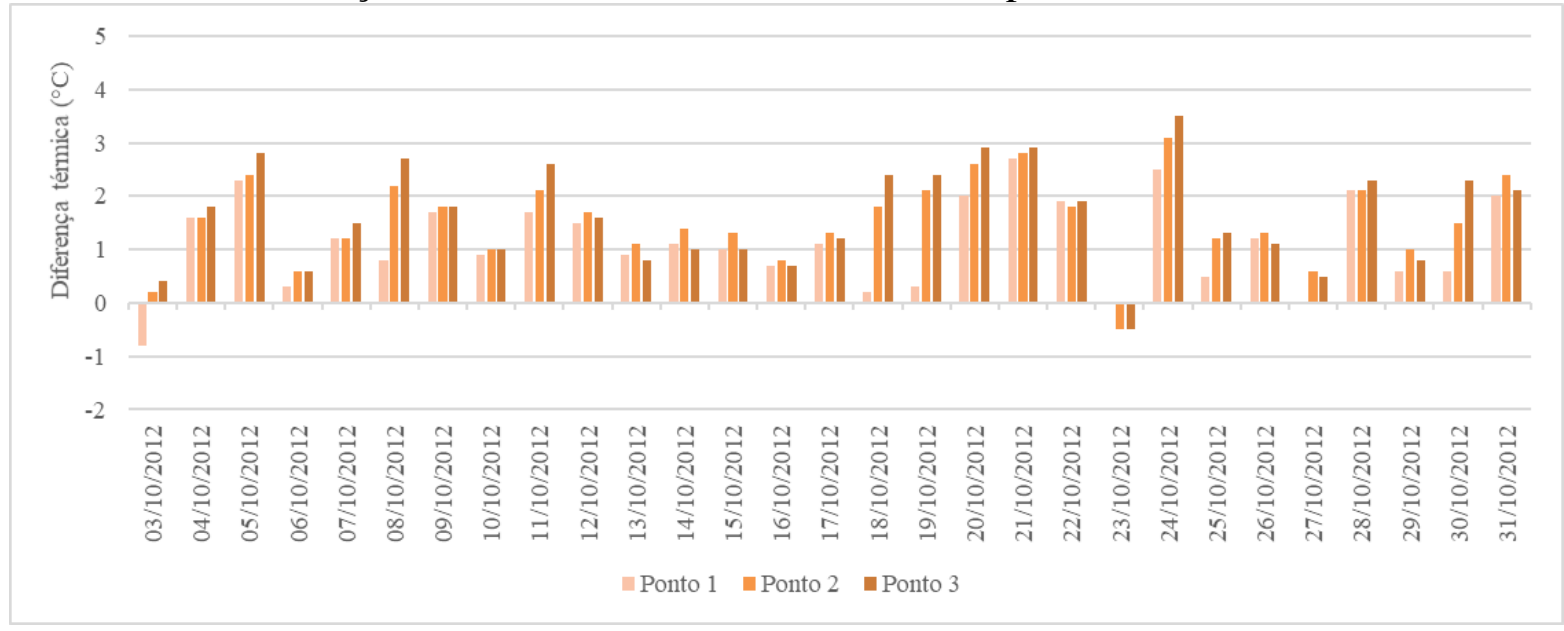

Fonte: autores.

No horário das $5 \mathrm{~h}$ foram registradas diferenças térmicas significativas entre os pontos urbanos e rural, sobretudo em dias representativos da estação da primavera. As diferenças térmicas no outono variaram de $-1,5^{\circ} \mathrm{C}$ a $2,6^{\circ} \mathrm{C}$, enquanto que nos dias representativos da primavera tivemos o registro de $-1^{\circ} \mathrm{C}$ a $3,3^{\circ} \mathrm{C}($ Gráficos 3 e 4).

Nos dias 11, 13, 29,30 e 31 do mês de maio de 2012 foram registradas diferenças térmicas negativas, sobretudo quando comparados os pontos de registro rural e o ponto 1 , causadas por sistemas atmosféricos instáveis como FPA e Repercussão da FPA (Gráfico 3). 
Certamente estas diferenças foram causadas pelas características de entorno do ponto 1 , explicitadas anteriormente neste artigo.

Ao passo em que nos dias representativos da primavera foram registradas diferenças negativas em apenas dois dias. A estocagem do calor na superfície em dias com nebulosidade se fez mais presente, o que ocasiona altas temperaturas e diferenças importantes entre o rural e o urbano, sobretudo na estação da primavera na região de Presidente Prudente.

Dessa forma, como no horário da $1 \mathrm{~h}$ as diferenças térmicas foram mais significativas em dias representativos da primavera para o horário das 5 h, mantendo o padrão observado.

Gráfico 3 - Diferenças Térmicas Urbano-rural em Dias Representativos do Outono às 5h.

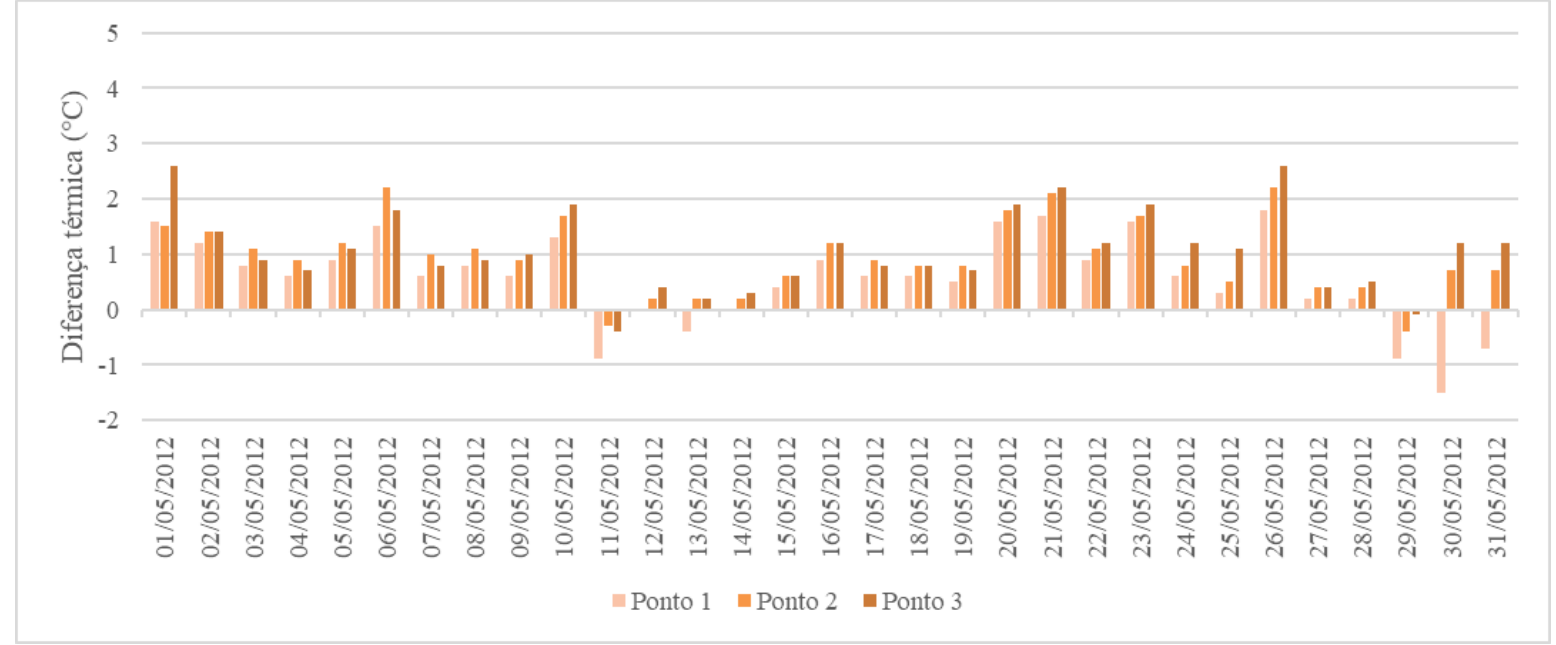

Fonte: autores.

Gráfico 4 - Diferenças Térmicas Urbano-rural em Dias Representativos da Primavera às 5h.

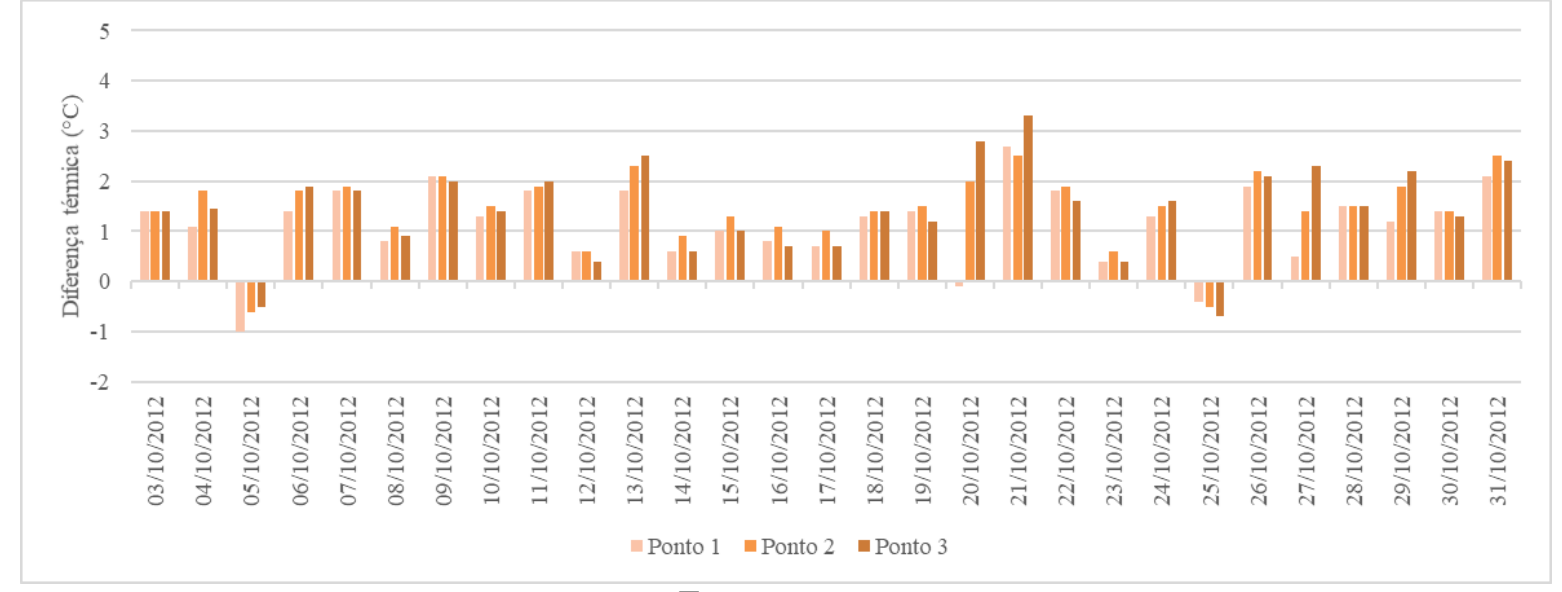

Fonte: autores.

Diversos estudos são realizados utilizando os dados meteorológicos registrados no período noturno, pois se sabe que o efeito máximo da ilha de calor pode ser observado nos horários desse período. 
Dessa forma, às $21 \mathrm{~h}$ foram registradas diferenças de até $4^{\circ} \mathrm{C}$ em dias representativos da estação do outono e de até $5^{\circ} \mathrm{C}$ em dias representativos da estação da primavera. As maiores diferenças térmicas analisadas neste artigo foram encontradas neste horário, seja em dias representativos da primavera ou do outono (Gráficos 5 e 6).

Gráfico 5 - Diferenças Térmicas Urbano-rural em Dias Representativos do Outono às 21h.

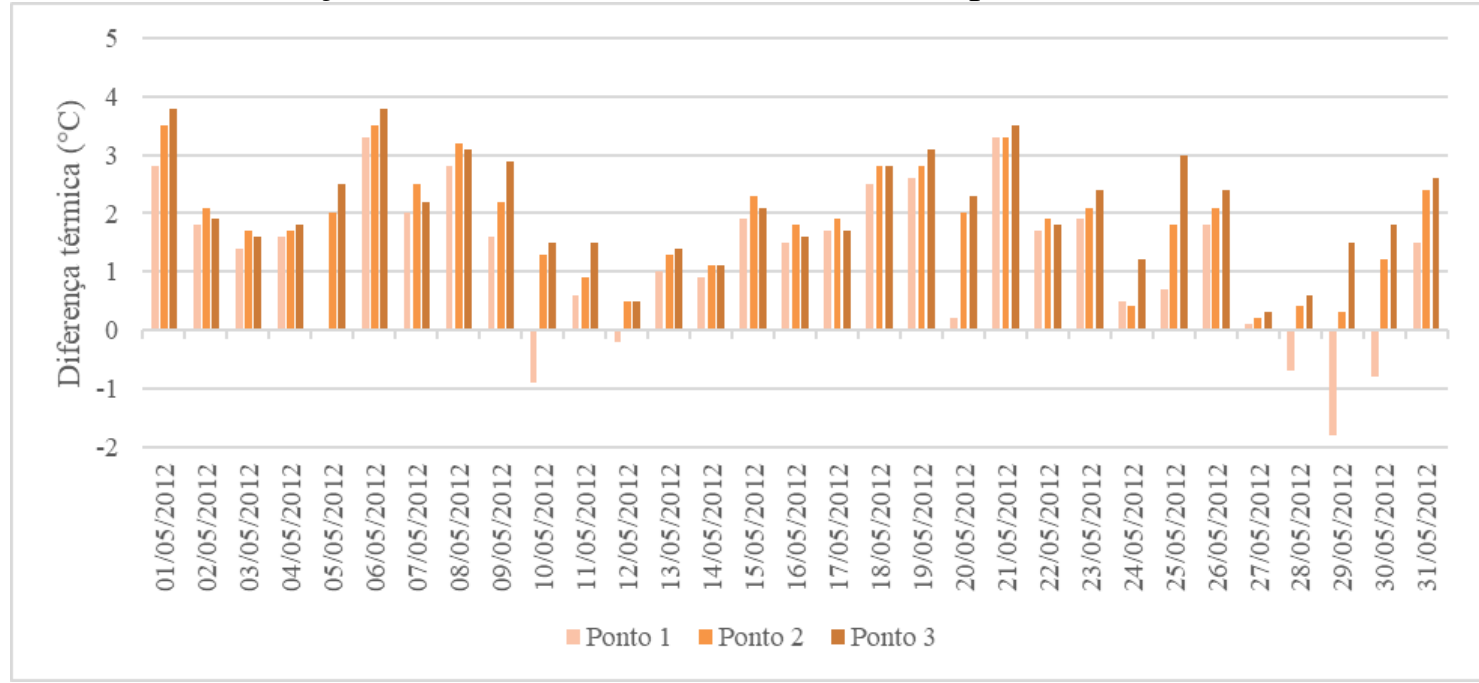

Fonte: autores.

Gráfico 6 - Diferenças Térmicas Urbano-rural em Dias Representativos da Primavera às 21h.

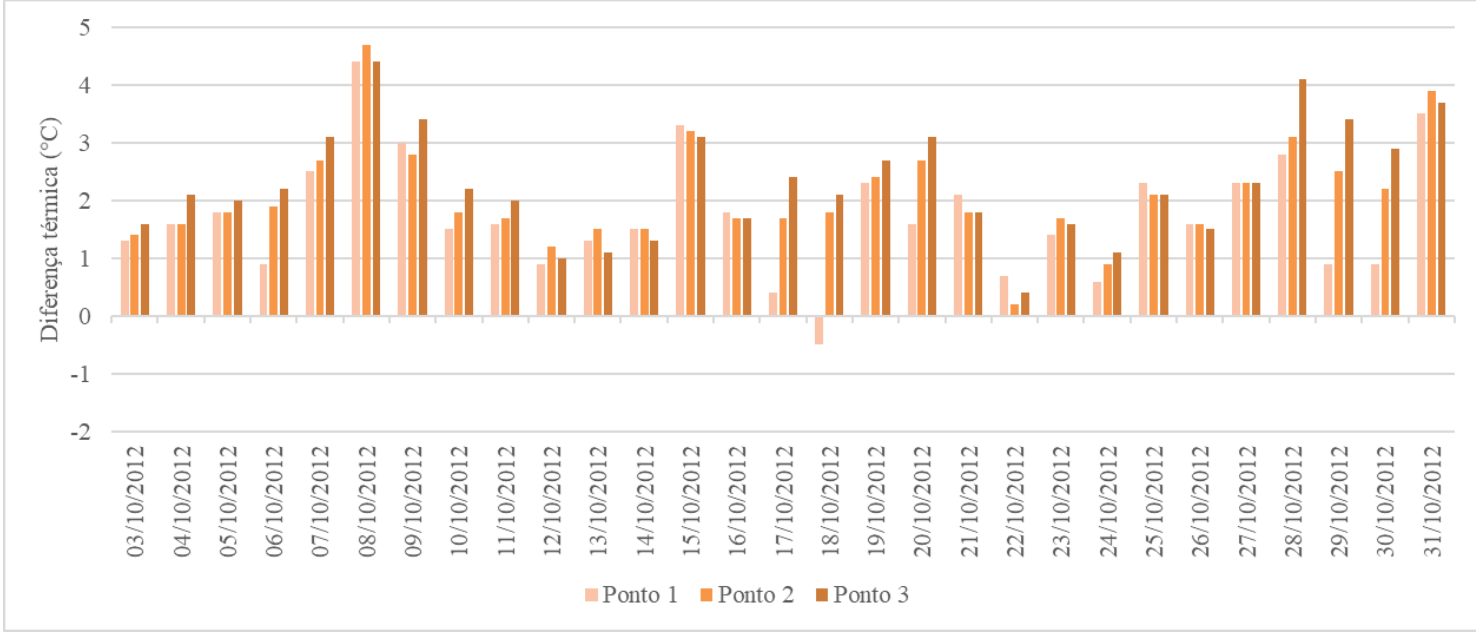

Fonte: autores.

É interessante explicitar que nesse horário as diferenças acompanharam o ritmo das precipitações muito mais que nos demais horários analisados. Em dias em que houve o registro de precipitação antes do horário das $21 \mathrm{~h}$, as diferenças diminuíram ou foram inexistentes, enquanto que em dias com condições de estabilidade atmosférica as diferenças foram mais expressivas que nos demais horários analisados.

Ainda neste horário, se consideramos o comparativo dos pontos de registro no urbano, tanto na estação do outono como na da primavera, o ponto 1 apresentou menores diferenças se doi.org/10.48075/geoq.v14i1.22472 
comparado ao ponto rural, enquanto os pontos 2 e 3 apresentaram maiores diferenças de temperatura do ar.

Neste contexto, podemos afirmar que quanto mais a superfície urbana for alterada, sobretudo, em detrimento da presença de superfícies com vegetação, maiores são os valores de temperatura do ar registrados.

O ponto 3, por apresentar áreas mais densamente construídas, apresentou maiores valores de temperatura do ar, enquanto no ponto 2 registrou-se temperaturas mais amenas e por fim, no ponto 1 , devido a significativa presença de vegetação e por estar próxima a um fundo de um vale, apresentou temperaturas mais baixas ${ }^{6}$.

\section{Síntese dos horários analisados}

Dois aspectos fundamentais foram importantes para a análise intraurbana e urbanarural dos dados meteorológicos registrados nos meses de maio e outubro de 2012 na área de estudo. Em primeiro lugar, a observação das condições geoecológicas e urbanas; e em segundo lugar, os sistemas atmosféricos atuantes e suas interações entre a superficie e a atmosfera, sejam estas urbanas ou rurais.

Pode-se observar que em grande parte dos dias analisados as diferenças de temperatura do ar foram maiores na estação da primavera. Nessa época do ano, para a região de Presidente Prudente, a atmosfera está mais quente e úmida, contribuindo assim para que as diferenças sejam mais expressivas entre os diferentes tipos de superfície devido ao tempo de liberação de calor nas superfícies urbanas e rurais.

A presença da vegetação é fundamental em horários com a presença dos raios solares, especialmente nas áreas com importantes corredores verdes, localizadas seja no interior dos quintais ou nas calçadas, propiciando assim uma amenização das diferenças entre as superfícies urbanizadas e não urbanizadas. No período noturno, a vegetação também desempenha um forte papel para a amenização das temperaturas, sobretudo nos espaços densamente urbanizados de cidades tropicais em que há a prevalência de valores térmicos elevados que contribuem para o desconforto.

\footnotetext{
${ }^{6}$ Ressalta-se que em alguns dias analisados (10/05, 12/05, 28/05, 29/05, 30/05 e 18/10), no ponto 1 foram registradas temperaturas mais baixas que na área rural, mostrando assim a importância da vegetação urbana de grande porte e dos espaços verdes presentes nas áreas residenciais, que têm o potencial de amenizar as altas temperaturas decorrentes da alteração da superfície urbana.
} 
As variações altimétricas contribuíram para as diferenças de temperatura do ar, pois no ponto 3 os valores de temperatura foram mais elevados em boa parte dos dias, enquanto no ponto de menor altitude, o ponto 1, os valores de temperatura registrados foram mais baixos. Dessa forma, ressaltamos a importância de estudos mais detalhados que levem em consideração os fatores de altitude e suas relações com a temperatura do ar, bem como a dinâmica dos ventos nestas áreas.

Em concordância com diversos estudos de climatologia urbana realizados no municipio de Presidente Prudente (AMORIM, 2000; AMORIM, 2005; AMORIM, DUBREUIL E CARDOSO, 2015; AMORIM, 2019), o presente estudo também mostrou que as diferenças são mais expressivas em condições de estabilidade, geradas pela atuação de sistemas atmosféricos estáveis, enquanto em dias de instabilidade, as diferenças tendem a diminuir entre os pontos de registro nas análises comparativas urbano-rural e intraurbanas.

A compreensão dos tipos de tempo é essencial para o entendimento e a explicação das ilhas de calor urbanas, apresentando valores mais importantes em condições de céu claro e calmaria (MONTEIRO, 1990; CANTAT, 2004).

Em síntese, a partir das análises dos horários 1h, 5h, 21h, foi possível observar as diferenças térmicas ocasionadas por diversos fatores, que em alguns momentos contribuíram para amenizá-las e em outros para potencializá-las. O entendimento das interações superfícieatmosfera em escala local e regional também foi um importante aliado para a compreensão destas diferenças térmicas.

Segundo García (1996), a intensidade das ilhas de calor é classificada como: fraca quando as diferenças de temperatura do ar entre os pontos oscilam entre $0^{\circ}$ e $2^{\circ} \mathrm{C}$, média entre $2^{\circ}$ e $4^{\circ} \mathrm{C}$, forte entre $4^{\circ}$ e $6^{\circ} \mathrm{C}$ e muito forte quando as diferenças ultrapassam os $6^{\circ} \mathrm{C}$. De acordo com as diferenças de temperatura do ar registradas no período noturno, podemos considerar então, a presença de ilhas de calor urbanas, no bairro de Jardim Maracanã em comparação com uma superfície rural, com intensidades que variaram de fraca a forte.

\section{Análise dos valores absolutos de temperatura do ar}

Os valores absolutos registrados em cada ponto, seja urbano ou rural, em dias representativos das estações do ano trabalhados neste artigo podem ser visualizados nos gráficos 7,8 e 9 . 
Foi possível observar que na maioria dos dias representativos da primavera os valores registrados estiveram acima dos $21^{\circ} \mathrm{C}$, sobretudo no horário das $21 \mathrm{~h}$. Neste mesmo horário, foram registrados valores superiores aos $26^{\circ} \mathrm{C}$. Outro fato que merece destaque é a permanência destes valores no horário da $1 \mathrm{~h}$, provavelmente explicado pelas características da estação da primavera, em que a atmosfera tende a estar mais úmida e com importante presença de nuvens que inibem a liberação do calor pela superfície, dessa forma, estocando o calor durante mais tempo na atmosfera local próxima a cidade.

Para os valores de temperatura do ar registrados em dias representativos do outono, é interessante notar que estes estiveram mais baixos, o que é normal para o período. A influência de sistemas atmosféricos oriundos do Sul do país contribui para o declínio das temperaturas, sobretudo em horários que antecedem o nascer do sol e do período matutino.

Diversos estudos realizados no domínio da climatologia urbana, sobretudo aqueles que investigam o fenômeno das ilhas de calor urbanas, priorizam a coleta de dados em campo nas estações do verão e do inverno, denominadas "estações extremas". Entretanto, diferenças térmicas importantes, também são registradas nos meses de outono e primavera, e servem como importantes resultados a serem integrados para a compreensão das interações entre a superfície urbana e a atmosfera local.

No caso deste estudo, através dos valores registrados podemos constatar que o fenômeno da ilha de calor urbana é significativo, mesmo na escala de um bairro. E que os valores registrados em campo revelam a permanência de altas temperaturas em diferentes momentos do período noturno, contribuindo assim, para o desconforto térmico dos citadinos.

Gráfico 7 - Valores Absolutos de Temperatura Registrados em Cada Ponto à $1 \mathrm{~h}$.

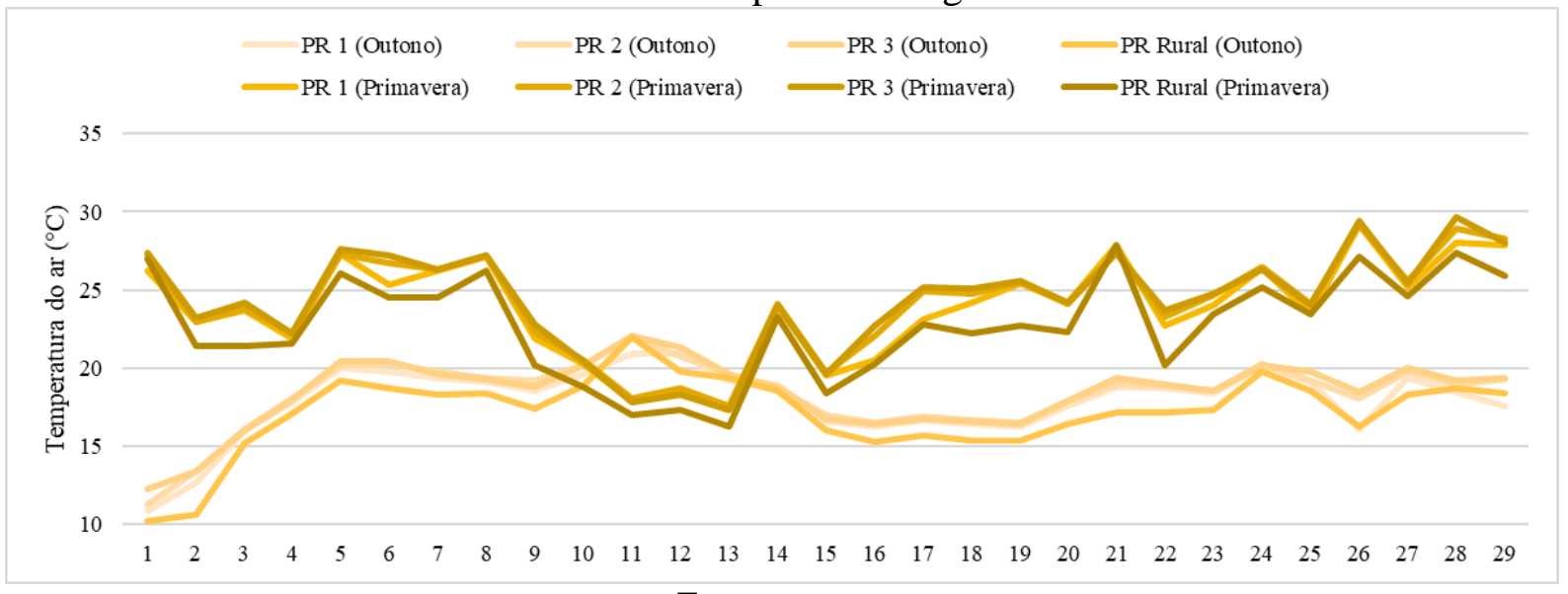

Fonte: autores. 
Gráfico 8 - Valores Absolutos de Temperatura Registrados em Cada Ponto às $5 \mathrm{~h}$.

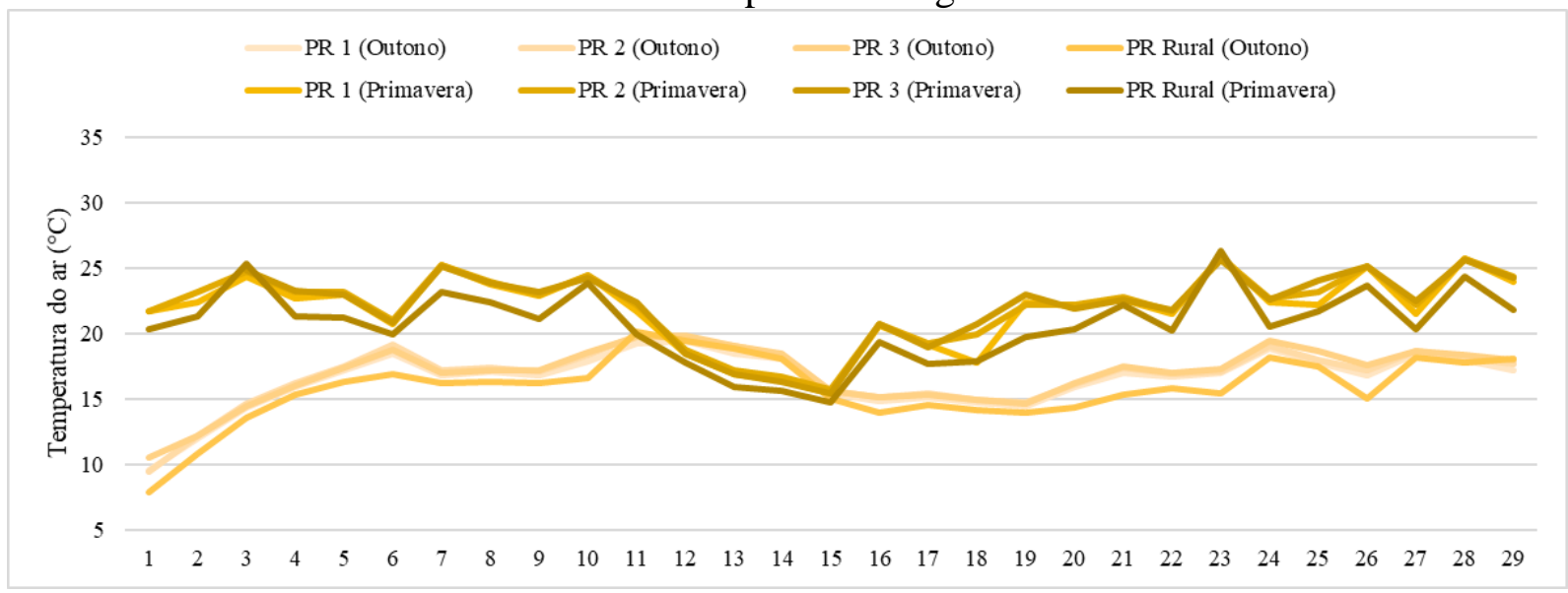

Fonte: autores.

Gráfico 9 - Valores Absolutos de Temperatura Registrados em Cada Ponto às $21 \mathrm{~h}$.

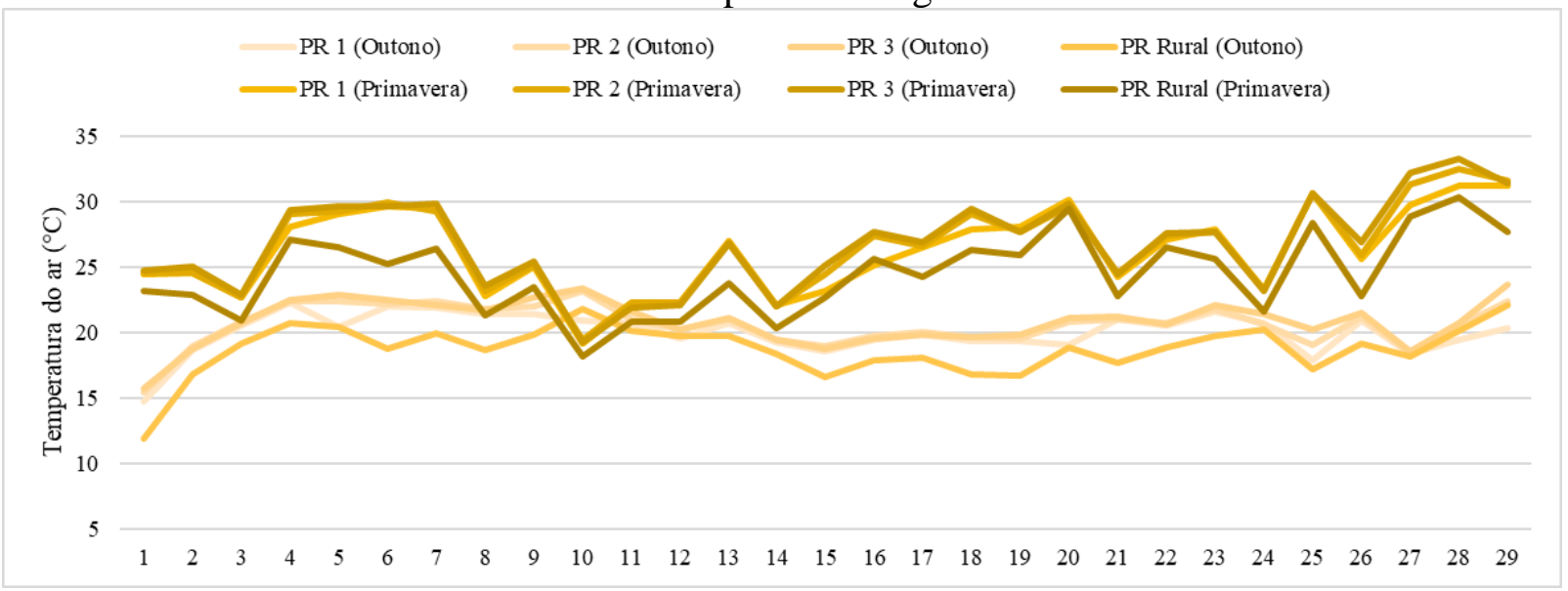

Fonte: autores.

\section{Considerações finais}

Os resultados apresentados neste artigo são extraídos da análise da temperatura do ar em dias representativos dos meses de maio e outubro de 2012. As diferenças térmicas registradas no bairro Jardim Maracanã e no entorno rural próximo à cidade de Presidente Prudente permitiram a identificação de episódios de ilhas de calor urbanas na escala de um bairro. É importante atualizar os dados meteorológicos coletados em 2012 para analisar a evolução das ilhas de calor urbanas em função das mudanças no uso e ocupação do solo em diferentes situações sinóticas.

O ponto de registro localizado em uma área densamente construída com pouca vegetação foi identificado como o mais aquecido, e para os outros dois pontos, também 
localizados em áreas densamente construídas mas com uma maior taxa de vegetação nas calçadas e no interior dos lotes, os valores de temperatura do ar registrados estavam mais próximos aos observados na área rural.

É importante salientar que ações (individuais e públicas) que apontem para uma ampliação de infraestruturas verdes nas áreas urbanas devem ser implementadas, contribuindo, desta forma, para a amenização dos constantes episódios de calor, especialmente no período noturno dos meses de primavera, como observado neste estudo.

\section{Referências}

AMORIM, Margarete Cristiane de Costa Trindade. Ilhas de calor superficiais: frequência da intensidade e variabilidade espacial em cidade de clima tropical continental. Geo UERJ, Rio de Janeiro, n. 34. 2019.

AMORIM, Margarete Cristiane de Costa Trindade. Intensidade e forma da ilha de calor urbana em Presidente Prudente/SP: episódios de inverno. Geosul, v.20, n.39, 2005.

AMORIM, Margarete Cristiane de Costa Trindade. O clima urbano de Presidente Prudente/SP. São Paulo: - Faculdade de Filosofia, Letras e Ciências Humanas da Universidade de São Paulo, 2000. 374p. (Tese, doutorado em Geografia: Geografia Fèsica).

AMORIM, Margarete Cristiane de Costa Trindade. Os climas urbanos em cidades localizadas na Raia Divisória São Paulo - Paraná - Mato Grosso do Sul. In: PASSOS, Messias Modesto dos. (org.), A raia divisória São Paulo Paraná Mato Grosso do Sul (Cenas e Cenários). 1. ed. São Paulo: Outras expressões, 2011. p. 133-166.

AMORIM, Margarete Cristiane de Costa Trindade; DUBREUIL, Vincent; CARDOSO, Renata dos Santos. Modelagem espacial da ilha de calor urbana em Presidente Prudente (SP) -Brasil. Revista Brasileira de Climatologia, v. 16. 2015.

ARMANI, Gustavo e GALVANI, Emerson. Avaliação do desempenho de um abrigo meteorológico de baixo custo. In: X Reunión Argentina y IV Latinoamericana de Agrometeorología. 2005, Buenos Aires. Anais... Buenos Aires. Disponível em: <agro.unc.edu.ar/ clima/AADA/Congresos/MDQ/116.htm> Acesso em: 12 mai. 2012.

BRASIL, Instituto Brasileiro de Geografia e Estatística. Censos demográficos e populacionais. Rio de Janeiro: IBGE, 2010. Disponível em: <http://www.ibge.gov.br/> Acesso em: 4 dez. 2014.

BRASIL, Instituto Brasileiro de Geografia e Estatística. IBGE CIDADES@. Rio de Janeiro: IBGE, 2014. Disponível em: < http://www.cidades.ibge.gov.br/xtras/home.php> Acesso em: 10 dez. 2014. 
CANTAT, Olivier. L'îlot de chaleur urbain parisien selon les types de temps. Revues Norois (Online), 2004, p. 75-102. Disponível em: <http://norois.revues.org/1373> Acesso em: 14 nov. 2013.

CARDOSO, Renata dos Santos; AMORIM, Margarete Cristiane de Costa Trindade. (2018). Urban heat island analysis using the 'local climate zone' scheme in Presidente Prudente, Brazil. Investigaciones Geográficas, 107-118. https://doi.org/10.14198/INGEO2018.69.07

GARCÍA, FERNÁNDEZ F. Manual de climatologia aplicada: clima, médio ambiente y planificación. Madrid: Editorial síntesis, S.A., 1996. 285p.

GARTLAND, Lisa. Ilhas de calor: como mitigar zonas de calor em áreas urbanas. Tradução: Sílvia Helena Gonçalves. São Paulo: Oficina de Textos, 2010.

LIMA, Nádia Gilma Beserra; GALVANI, Emerson; FALCÃO, Rita Monteiro. Análise da temperatura do ar no perfil topoclimático do pico da bandeira, Parque Nacional Alto Caparaó, Brasil, entre as altitudes de $1106 \mathrm{~m}$ a $2892 \mathrm{~m}$. In: VI Seminário Latino-Americano de Geografia Física e II Seminário Ibero-Americano de Geografia Física, 2010, Coimbra. Anais... Universidade de Coimbra, 2010.

LUCENA, Andrews José de. Notas conceituais e metodológicas em clima urbano e ilhas de calor. Revista Continentes (UFRRJ), ano 2, n.2, 2013. 32p.

MENDONÇA, Francisco de Assis. Riscos e Vulnerabilidades socioambientais urbanas: a contingência climática. Mercator (UFC), v. 9, p. 153-163, 2010.

MONTEIRO, Carlos Augusto de Figueiredo. Teoria e Clima Urbano. São Paulo: Instituto de Geografia, Faculdade de Filosofia, Letras e Ciências Humanas, Universidade de São Paulo. São Paulo, 1976. 181p. (Série Teses e Monografias, n. 25).

MONTEIRO, Carlos Augusto de Figueiredo. Adentrar a cidade para tomar-lhe a temperatura. Geosul, v.20, n.9, 1990.

OKE, Timothy R. Boundary Layer Climates. London: Methuem \& LTD. A. Halsted Press Book, John Wiley \& Sons, New York, Second Edition, 1987. 372p.

SANTOS, Milton. A urbanização brasileira. São Paulo: Edusp - Editora da Universidade de São Paulo, 1993. 176 p.

SAYDELLES, Alexandre Pistoia. Estudo do campo térmico e das ilhas de calor urbano em Santa Maria - RS. Santa Maria, 2005. Dissertação (Mestrado em Geografia e Geociências) - Universidade Federal de Santa Maria. 2005. 